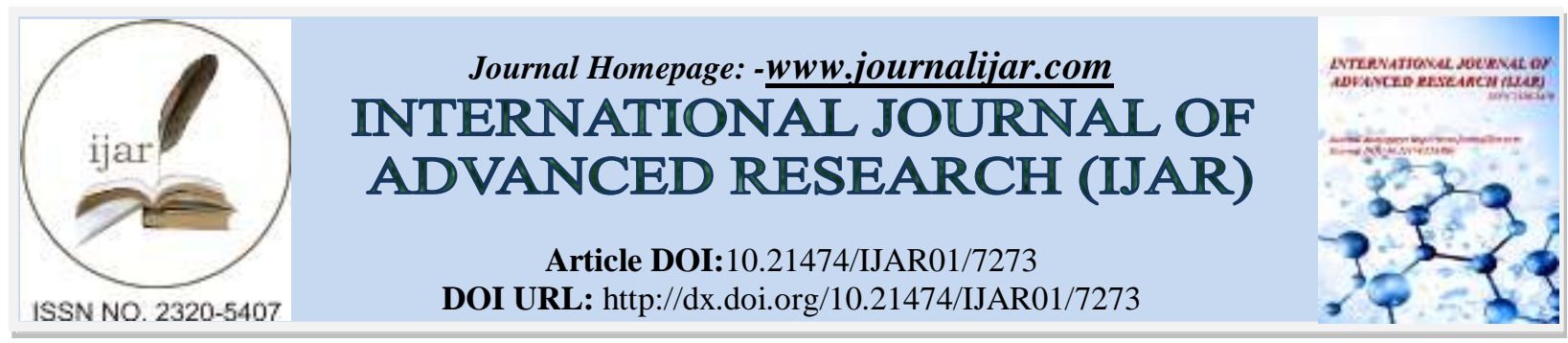

RESEARCH ARTICLE

\title{
"ETIOPATHOLOGICAL STUDIES ON HAEMOPARASITIC INFECTIONS OF HORSES IN MALWA REGION OF MADHYA PRADESH".
}

\author{
L. Waskel, S. Shukla, A. Sharma, D. Chhabra, G. P. Jatav and M. A. Khan. \\ Department of Veterinary Pathology, College of Veterinary Science \& A.H., Mhow, NDVSU, Jabalpur (MP) \\ 453446.
}

\section{Manuscript Info}

Manuscript History

Received: 12 April 2018

Final Accepted: 14 May 2018

Published: June 2018

Keywords:-

Equine Piroplsmosis, Trypanosomiasis, Incidence and Malwa region.

\begin{abstract}
Equine Piroplasmosis and Trypanosomiasis is the considered as major threat against horse management. A study was conducted of malwa region in M.P. to know the etiopatholgy of haemoparasitic infections. Out of 100 horses, 29 horses were found positive for haemoparasitic infections. The parasites were identified on the basis of characteristic morphology. The incidence of Trypanosomiasisinfection was highest in Malwa region viz. (18\%) followed by Theileriosis (09\%) and Babesiosis infections (02\%). Female horses were affected more than male horses and highest incidence was recorded in Rainy season.
\end{abstract}

Copy Right, IJAR, 2018,. All rights reserved.

\section{Introduction:-}

The total equine population in the world is about 59 million horses, 44 million donkeys and 11 million mules. In most of the developing countries, more than $72 \%$ of the world's horse population and over $97 \%$ of the world's donkey and mule population are kept specifically for work. Among the multiple health and welfare problems affecting working equids, parasitic diseases such as equine Piroplasmosis (EP) and Trypanosomiasis are major constraints of their performance and productivity, often leading to high morbidity and mortality. The EP was first reported in Sudan by Oliver 1907 (cited by Abdoon, 1984). It is a disease of equids caused by the intracellular, haemoprotozoan parasite Babesia equi, reclassified as Theileria equi and Babesia caballi. In 1901, Theiler, perceived intra-erythrocytic parasites in blood samples. The clinical sign of the haemoparasitic infection observed in equids in Pretoria, South Africa, were similar to human malaria infection (plasmodiidae) so he assigned, it to be "equine malaria." Later on Laveran (1901) acclaims it as intra erythrocytic piroplasms. Blood and lymph node fluid smears microscopic detection of the piroplasm and schizonts from the suspected host is the true "Gold Standard" diagnostic test available for EP still, in T. equi infection lymph node biopsies along with the clinical signs (enlargement of lymph nodes and high fever of $104^{\circ} \mathrm{C}$ ) of the disease also help in detection (Sumbria and Singla, 2015). Trypanosoma evansi was first isolated from infected camels and equids in the Dera ismail khan District of Punjab in 1880 by a British Veterinarian Griffith Evans. The incidence and the severity of diseases varies in different localities according to the strain of $T$. evansi. There is evidence that $T$. evansi causes enormous loss to livestock when the infection is initially introduced into new areas, in the Indian sub-continent. An increase in surra has been associated with mansoon months, reaching the climax in October and November when the flie breeding is at its highest. Surra in equines invariably proves fatal. The chief symptoms are high rise of temperature, anaemia, general urticarial eruptions and petechial hemorrhages (Pathak and Singh, 2005). In india much work has been carried out including slide examination, serological test and nucleic acid detection of parasites (Pathak and Singh, 2005). However, Madhya Pradesh till date is lacking in these preliminary areas of recording and diagnosis of equine Piroplasmosis and Trypanosomiasis. 


\section{Materials and Methods:-}

For the present study blood samples of 100 horses were collected from TVCC, Mhow, organised and private equine stables, equine organizations and individual horse owners and were screened for haemoparasitic infections, types of anaemia's and liver and kidney function status of affected horses.

\section{Results and Discussion:-}

Out of 100 horses, 29 horses were showing emaciation, fever, hemoglobinurea, ataxia, circling movement, parasitaemia, anemia and icterus suggestive of heamoparasitic infections. Microscopic examination was done by modified Wright stain for all heamoparasites. The parasites were identified on the basis of characterstics morphology. Following results were drawn from the study. The incidence of Trypanosomiasis infection was found to be highest (18\%), in Malwa region. Overall incidences are presented in Table 01.

Table 01:-Overall incidence of haemoparasitic infections including Piroplasmosis and Trypanosomosis in horses (Total no. of cases 100)

\begin{tabular}{|l|l|l|}
\hline Infections & Number of positive cases & Overall Incidence \\
\hline Trypanosomiasis & 18 & $18 \%$ \\
\hline Theileriosis & 09 & $09 \%$ \\
\hline Babesiosis & 02 & $02 \%$ \\
\hline Anaemias of unknown origin & 11 & $11 \%$ \\
\hline
\end{tabular}

The incidence of Trypanosomiasis infections was found to be highest in Malwa region viz. (18\%) followed by Theileriosis (09\%) and Babesiosis (02\%) infections as confirmed by blood smears examination. This incidience is in agreement with the findings of Chavda et al. (2015) and Singh et al. (2016) who mentioned in their study about equal incidence of parasitic infection in Anand and Mathura respectively and in contrast, with the findings of Mavadiya et al. (2010), Shyam et al. (2013) and Salim et al. (2014) who noted more number of other parasitic infections.

Table 02:-Gender wise incidence of haemoparasitic infections including Piroplasmosis and Trypanosomiasis in horses $(n=100)$

\begin{tabular}{|l|l|l|}
\hline Infections & Male & Female \\
\hline Trypanosomiasis & $04(4 \%)$ & $14(14 \%)$ \\
\hline Theileriosis & $03(3 \%)$ & $06(6 \%)$ \\
\hline Babesiosis & $01(1 \%)$ & $01(1 \%)$ \\
\hline
\end{tabular}

$\mathrm{X}^{2}=0.42^{\mathrm{NS}}$

$\mathrm{NS}=$ Non significant, Chi square is found to be non significant at $5 \%$ level of significance $\mathrm{n}=$ percent in parenthesis

The sex-wise incidence rate of Trypanosomiasiswas higher in female (14\%) followed by male $(04 \%)$ and in Piroplsmosis (Theileria equi \& B. caballi), also females (7\%) were more affected compare to male (04\%). These findings are in agreement with the reports of Mavadiya et al. (2010), Bahrami et al. (2014),Javed et al. (2014), Chavda et al. (2015) and Bhojani (2016), who reported that the male appears to be less affected than the female. The reason for the difference was probably due to greater population of female than male and gelding, the management factors and difference in vector population of the areas.

Table 03:-Age wise incidence of haemoparasitic infections including Piroplasmosis and Trypanosomiasis $(\mathrm{n}=100)$

\begin{tabular}{|l|l|l|l|}
\hline Infections & $\mathbf{2 - 5}$ year & $\mathbf{5 - 1 0}$ year & Above 10 year \\
\hline Trypanosomiasis & $03(3 \%)$ & $10(10 \%)$ & $05(5 \%)$ \\
\hline Theileriosis & $02(2 \%)$ & $04(4 \%)$ & $03(3 \%)$ \\
\hline Babesiosis & $00(0 \%)$ & $01(1 \%)$ & $01(1 \%)$ \\
\hline
\end{tabular}

$\mathrm{X}^{2}=0.94^{\mathrm{NS}}$

NS=Non significant, Chi square is found to be non significant at $5 \%$ level of significance $\mathrm{n}=$ percent in parenthesis 
Higher incidence rate of Piroplasmosis in adult group of horses followed by aged and yearling group of horses in present findings have close similarity with the findings obtained by Javed et al. (2014) and Bhojani (2016). The disease may be associated with the number of animals under study, the different diagnostic methods used, the geographic area and difference in vector population between these areas. However, stress, inadequate nutrition, inadequate exercise, close confinement, transportation and managemental negligence might have played a vital role for predisposing the disease in adult group.

Table 04:-Season wise incidence of haemoparasitic infections including Piroplasmosis and Trypanosomiasis $(\mathrm{n}=100)$

\begin{tabular}{|l|l|l|l|}
\hline Group & March-June & July-October & November-February \\
\hline Trypanosomiasis & $02(2 \%)$ & $10(10 \%)$ & $06(6 \%)$ \\
\hline Theileriosis & $01(1 \%)$ & $05(5 \%)$ & $03(3 \%)$ \\
\hline Babesiosis & $00(0 \%)$ & $01(1 \%)$ & $01(1 \%)$ \\
\hline
\end{tabular}

$\mathrm{X}^{2}=9.73$

Chi square is found to be highly significant $(\mathrm{p}<0.01)$ at $1 \%$ level.

$\mathrm{n}=$ percent in parenthesis

A total 100 cases of horses were registered, in which $16(16 \%)$ came in rainy season, $10(10 \%)$ in winter season and $03(3.0 \%)$ in summer season. The season-wise incidence rate of Trypanosomiasiswas higher in rainy season (10\%) followed by winter season $(06 \%)$ whereas less incidence was observed in summer season $(2.0 \%)$. Chavda et al. (2015), reported similar findings of highest number of cases in rainy season followed by winter season and lowest in summer season. Probable reason for the disease occurrence was associated with considerable rain fall and sprung grass which is the most suitable environment for the breeding of tabanids. Basu et al. (1952), observed that the incidence of surra and tabanids was co-extensive. Surra has seasonal distribution, since it commences a few weeks after the onset of monsoon in late May through June over most of the India.

In Piroplasmosis the season-wise incidence rate was recorded higher in rainy season $(6.0 \%)$ followed by winter season (4.0\%) while lower incidence was recorded in summer season (1.0\%). According to blood smear examination of suspected horses, the incidence of Piroplasmosis was 11\% in Malwa region. The present findings are similar for T. equi with Salib et al. (2013) and for B. caballi, in contrast with Javed et al. (2014), who reported, maximum cases in summer followed by winter and lowest in monsoon season in Pakistan. Supporting the view that the prevalence of blood protozoan parasitic diseases is depending upon the vector population of the particular region. Based on blood smear examination of haemoparasites may not be revealed in early stage of infection. Carrier animals are thought to be responsible for the maintenance of the infection. In these animals, parasites are present in very low numbers in the blood and they may not be detected in Giemsa-stained blood smears.

\section{Conclusion;-}

Incidence of infections varying found to be $29 \%$ in blood samples of horses. Cases of Trypanosomiasis (18\%), Theileriosis (09\%) and Babesiosis infections $(02 \%)$ were determined and differentiated. The highest cases were found in Trypanosomiasis infection.In the Rainy season the highest incidence was recorded. Female horses were more affected as compare to male horses. 


\section{Reference:-}

1. Abdoon, A.M.O. (1984). Studies on some aspects of equine piroplasmosis in khartoum district, Sudan. M.Sc. Dissertation University of khartoum: 85.

2. Bahrami, S., Ghadrdan, A.R., Mirabdollahi, S.M. and Fayed, M.R. (2014). Diagnosis of subclinical equine theileriosis in center of Iran using parasitological and molecular methods. Tropical Biomedicine, 31(1):110-117.

3. Basu, B.C., Menon, P.B. and Sen Gupta, C.M. (1952). Regional distribution of Tabanus flies in India and its relationship to the incidence of surra. Indian Journal of Veterinary Science, 22:273-292.

4. Bhojani, R.J. (2016). Epidemiological and diagnostic studies on piroplasmosis in horses M. V. Sc. Thesis. Rajasthan University of Veterinary and Animal Sciences, Bikaner.

5. Chavda, K.J., Mandali, G.C. and Tank, P.H. (2015). Diagnosis and therapeutic management of horses infected with Trypanosoma evansi. The blue cross book, 32:91-94.

6. Evans, G. (1880). Report on surra disease in dera ismail khan district, Punjab government military department no. 493 pp 4467.

7. Javed, K., Ijaz, M., Ali, M.M., Khan, I., Mehmood, K. and Ali, S. (2014). Prevalence and haematology of tick borne haemoparasitic diseases in equines in and around Lahore. Pakistan of Journal,46(2):401-408.

8. Laveran, A. (1901). Contribution a l'etude de Piroplasma equi. CR Soc. Biol,53, 385- 388.

9. Mavadiya, S.V., Raval, S.K. and Mehta, S.A. (2010). Epidemiological aspects of Trypanosome evansi infection in horses. Indian Journal Field Veterinary, 6(1):51-53.

10. Pathak, K.M.L. and Singh, N. (2005). Animal Trypanosomosis. Intas Polivet,6(11):194-199.

11. Salib, F.A., Youssef, R.R., Rizk, L.G. and Said, S.F. (2013). Epidemiology, diagnosis and therapy of Theileria equi infection in Giza, Egypt. Veterinary World, 6(2):76-82.

12. Salim, B., Bakheit, M.A. and Sugimoto, C. (2014). Molecular detection of equine Trypanosomes in the sudan. Veterinary Parasitology, 200:246-250.

13. Shyam, K.P., Gupta, S.K., Singh, A., Chaudhary, S.S. and Gupta, J.P. (2013). Detection of Trypanosoma evansi in whole blood of domestic animals by DNA amplification method. Indian Journal of Animal Research, 47(5):456-459.

14. Singh, R.K., Tripathi, A.K., Singh, S.K. Singh., A.P. and Yadav, S.C. (2016). Seroprevalence epidemiological studies on equine Trypanosomosis usingAb-ELISA in a part of semi-arid zone of northern plains of India. Indian Journal of Animal Sciences, 86(7):743-745.

15. Sumbriya, D and Singh, L.D. (2015). Recent diagnostic and control approaches in Equine Piroplasmosis. Veterinaria, 2(1):29-32

16. Theiler, A. (1901). Die Pferde-Malaria. Schweizer Archiv für Tierheilkunde, 43, 253-280. 